\title{
Research Design of Intelligent Tourist Guide System and Development of APP
}

\author{
Kaijian Huang ${ }^{1, a}$ and Junwu Zhu ${ }^{2, b}$ \\ ${ }^{1}$ School of Information Engineering, Yangzhou University, Yangzhou, China \\ ${ }^{2}$ Department of Computer Science and Engineering, Nanjing University, Nanjing, China \\ ahuangkaijian0803@163.com, bjwzhu@yzu.edu.cn
}

Keywords: Guide Service; Intelligent Tourist Guide System; Shortest Path Algorithm; Android

\begin{abstract}
The developing tourist industry proposes higher and higher demands to the intelligent tourist guide system, which can take place of the traditional artificial guide service. Functions of intelligent automatic interpretation, real time navigation, intelligent route planning and surrounding service reminder are included in it. With rapid development of electronic information technology and computer technology as the support, this thesis combines with the shortest path algorithm and related knowledge of graph theory to design algorithm and processing scheme. Moreover, this thesis also introduces research design of intelligent tourist system as well. Thus, the function of APP on the android platform is realized.
\end{abstract}

\section{Introduction}

With the development of national economy, formation of a new life concept and the perfection of vacation system, tourism has become more and more people's choice during the holidays. Its market is broad and potential. At present, the main way for guide service is the artificial guide service, which have many shortcomings. Such as the insufficient number of tour operators, the high cost of artificial guide service, the quality of tour guides' explaining and noise pollution, which cause tourists to be dissatisfied with the current traditional tourist guide service quality.

Previous electronic tourist guide system mainly designed some equipment with electronic information technology [1]. The main content is information related to historical and cultural background, which is in multimedia form. Its function is realized by operation of tourists or staff. This system is usually designed for one specific scenic spot. It cost much for the scenic. Moreover, it is inconvenient for tourists to operate, and services it supply are limited. With developing tourism and refining demands from tourists, previous systems can not meet the current situation. As the tourist is the key of guide services, we must carry out theoretical study and practical design on intelligent tourist guide systems base on the tourists’ demands.

\section{Related Studies on Intelligent Tourist Guide System}

Research on intelligent tourist guide system first started in European and American countries in 1990s. Because of close relationship among its development, electronic technology, and market demand, related research on this system soon become the research focus of scholars and enterprises, with scientific and technological progress and tourism industry development.

\section{Abroad}

Studies abroad have already been superior to studies at home on theoretical studies and technical practice on this study. On one hand, their tourism and related service industry began earlier than China, which lead to their advanced research. On the other hand, technology in developed countries surpassed China, which is the basis of research.

At present, most scenic spots have adopted electronic guides in developed countries, especially indoor exhibition halls such as museum. Electronic guide system was designed and put in use by Abowd, Atkeson and their partners in 1996 [2]. In 2011, H. H. Owaied linked artificial intelligence 
to intelligent tourist guide system and came up with a research model which is composed of the user interface, knowledge base, dynamic link library, inference engine and application apparatus [3].

\section{At Home}

As to the current tourism industry situation in China, the potential market of electronic intelligent guide is very broad. And some related researches have been carried out, which include theoretical and practical research issues.

On theoretical aspects, Guo Junfeng from Qingdao University completed his master's thesis by a comprehensive research and analysis on self-help electronic tourist guide system [4], and summarized the respective characteristics and differences of electronic guide and traditional artificial guide, which supports the following study of intelligent tourist guide system.

On practical aspects, China began to try to replace traditional manual guide service with electronic tour guide service in twentieth Century, such as Lijiang River, Shanxi Yellow Emperor Mausoleum, Tianjin museum. But the main form used is digital buttoned machine. Its form and function is original and sole without intelligence.Then in Beijing, such as Tiantan Park, and the Summer Palace began to appear according to the wireless signal induction can automatically electronic guide system interpretation service.

\section{Questions}

Based on the current status and development of intelligent navigation and electronic guide , this thesis summaries up the following four problems need to be solved on its study.

- Question 1: Previous electronic guide system can only provide limited functions, such as historical and humanistic introduction of scenic spot in the form of text or voice for tourists, without location information, recommended route, surrounding guide services, which are basic functions.

- Question 2: Most scenic held electronic guide devices are button or touch screen type facilities set up in fixed location. Visitors can only access to these in the specific place. Some scenic spots may provide mobile hand-held devices, which is inconvenient for tourists to take and influences their travailing experienced.

- Question 3: In practical usage, electronic guide system need to define and divide range of attractions. Most of the current schemes are WiFi signals or signal source point layouts of a RFID in some spots, which set the effective signal coverage to fit the size of the scenic spots. But in fact The region of one attraction rarely is round or other regular shape, some attractions region even presents crescent or irregular, narrow rectangular.

\section{Framework of Intelligent Tourist Guide System}

System Model of the Research Project

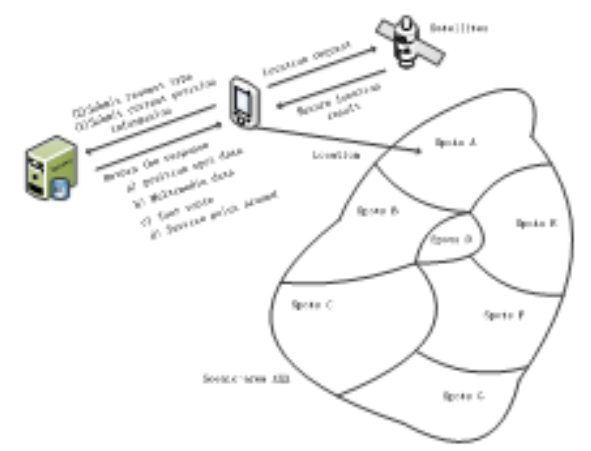

Fig. 1. Model for the Research Object 


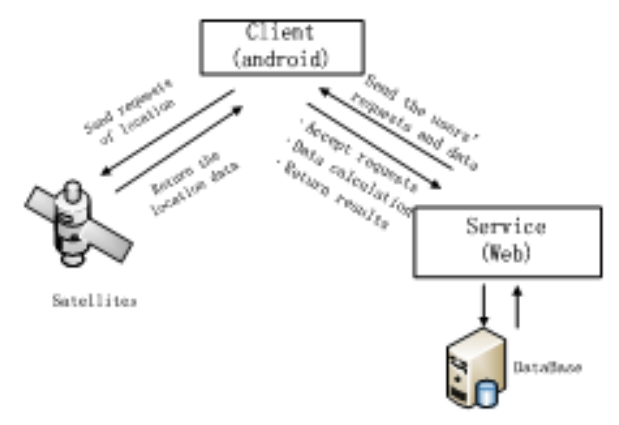

Fig.2. System Frame

Problem description: As shown above in Figure 1, when a tourist wants to go sight-seeing in XXX. However, if there is only one hour for scenic touring, he(or she) needs to select some scenic spots intelligently. Considering that the general tourists are not very familiar with the scenic spots, thus, this thesis assumes that this tourist was in the situation. It necessary to make a choice of the scenic spots, the route and the sequence. What's more, he(or she) also needs to know how to get the related information about the history and culture of this area, and surrounding service.

\section{System Overall Structure and Function Definition}

Programming language used in the system design is Java. Programming tool is Eclipse for

Android. The API for client orientation function involved is Baidu Map API, Baidu Location API and Tianditu API. These are all packages for open source share.

This thesis adopts the C/S architecture model as shown in above Figure 2. It studies the decoration of APP client on the android intelligent mobile phone and shows what service content in the system to the users and provides interactive interface of intelligent tourist guide system . System module is mainly divided into Android mobile phone client and a web server.

In final system as shown in Figure 3, this approach of this article is combined with A-GPS network aided positioning system function in Android own operating system. Then, it is optimizing the server fixed data real-time positioning by the precise positioning algorithm.

As shown below in Figure 4. Web server accepts the request sent from the android client, gets request data and calls after response results returned to the client program basing on service program execution encapsulation. Such as accurate positioning scheme after positioning, text or voice video data reflection to tourists about the history of the humanities of attractions place.

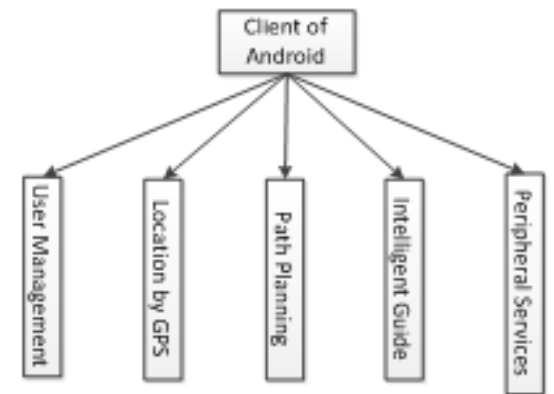

Fig.3. The Client Services Project

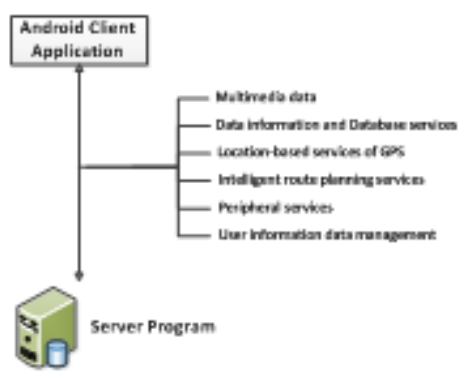

Fig.4. Functions of the Server

\section{Main Research contents}

Based on the GPS real-time location Research

At present, the main location technology is divided into the RFID [5], WiFi [6] and GPS [7].

- RFID is the main technical support of electronic guide studies. Most use of the existing related products on the market at present is on the scenic spot layout application RFID IC card of radio 
frequency identification technology, through customized hand-held devices. This the system need network installation hardware facilities, and hand-held devices need to be developed.

- WiFi to realize the location of the positioning function is the current popular acquisition method. WiFi is the more extensive use of a Wireless LAN technology in current scope, which is a kind of Wireless network industry standard defined by the IEEE, also called 802.11 standard. WiFi generally uses RSSI localization algorithm to achieve the positioning function.

- With GPS to realize real-time location tracking function. Global positioning system has been the most widely used all over the world. GPS has now developed into various areas such as land, sea, aviation, A variety of patterns are included such as GPS, A-GPS, DGPS.

Most of electronic guide systems implemented are usually specific custom-made equipment and software system for scenic spot. Some programs are equipment set up in a fixed position with display functions, providing the button or touch screen for tourists to choose or browse information. However, functions of provided service are simple, and it is inconvenient for tourists.

In recent years, intelligent mobile devices are in rapid expansion and in every corner of daily life. At present, the proportion of usage of android mobile phone is very high. There are some designs of guide type of APP based on the android operating system in the mobile market. But it is far from satisfaction of the huge demand from electronic guide market for functional or practical reason.

During the development of the intelligent guide APP, with the A-GPS function in smart phones and deviation-correction method, the precise position date of the tourists will be obtained.

As table.1, three times of locating test data in the same place:

Table. 1. Three Times Location Results

\begin{tabular}{|c|c|c|}
\hline \hline & Longitude & Latitude \\
\hline First & 119.395480 & 32.342634 \\
\hline Second & 119.395553 & 32.342621 \\
\hline Third & 119.395710 & 32.343605 \\
\hline
\end{tabular}

The Scope of the Scenic Spots Area

The currently wide used RFID radio frequency or WiFi wireless LAN coverage scheme can only be the defined by fuzzy scenic area, because the signal coverage is round or fan, while most attractions shape is irregular or complex. As signal source coverage scheme can not meet the needs of precise definition scenic area. In order to deal with the exact definition and plan of the scenic area, this paper links to the current global positioning technology. GPS is put forward to measure the longitude and latitude as coordinate data, and combined with the linear function group, establish 2D coordinate system scheme about the latitude and longitude to define and classify scenic areas.

As shown in Figure 5, scenic area XXX contains A G seven different spots. Precise scope definition of each scenic spot will help to judge which spot the tourists is in. Thus the system can provide the relevant service of the spot more accurately for the visitors. 


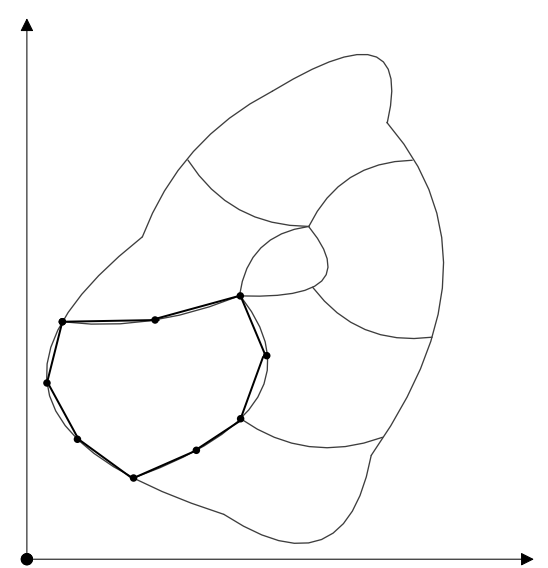

Fig. 5. Overall diagram of the scenic-area

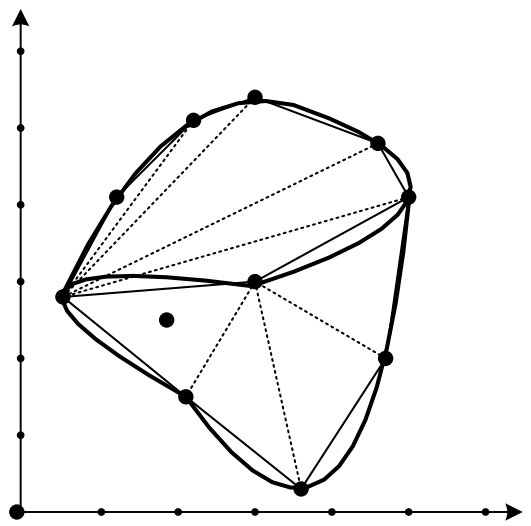

Fig. 6. Spot A and Spot B

The main ideas of scenic area planning is as following:

1) Establish a two-dimensional coordinate system based on the latitude and longitude. Assuming that Spot A and Spot B are adjacent, their regional distribution is shown as Figure 6.

Step 1: Choose appropriate points in the area on the border of $a_{1}, a_{2}, a_{3}, \ldots$ and $a_{10}$, the polygon linking up by $a_{1}$ to $a_{7}$ can be approximated as Spot $A$ area $\left(a_{1}, a_{2}, a_{3}, a_{4}, a_{5}, a_{6}, a_{7}\right)$, while the polygon linking up by $\mathrm{a}_{1}, \mathrm{a}_{6}, \mathrm{a}_{7}, \mathrm{a}_{8}, \mathrm{a}_{9}, \mathrm{a}_{10}$ can be approximated as Spot $\mathrm{B}$ area $\left(\mathrm{a}_{1}, \mathrm{a}_{6}, \mathrm{a}_{7}, \mathrm{a}_{8}, \mathrm{a}_{9}\right.$, $\mathrm{a}_{10}$ ).

Step 2: Divide Spot $A$ into 5 triangles as $\Delta \mathrm{a}_{1} \mathrm{a}_{2} \mathrm{a}_{3}, \Delta \mathrm{a}_{1} \mathrm{a}_{3} \mathrm{a}_{4}, \quad \Delta \mathrm{a}_{1} \mathrm{a}_{4} \mathrm{a}_{5}, \quad \Delta \mathrm{a}_{1} \mathrm{a}_{5} \mathrm{a}_{6}$, $\Delta \mathrm{a}_{1} \mathrm{a}_{6} \mathrm{a}_{7}$.Divide Spot B into 4 triangles as $\Delta \mathrm{a}_{1} \mathrm{a}_{7} \mathrm{a}_{9}, \Delta \mathrm{a}_{6} \mathrm{a}_{7} \mathrm{a}_{8}, \Delta \mathrm{a}_{7} \mathrm{a}_{8} \mathrm{a}_{10}, \quad \Delta \mathrm{a}_{7} \mathrm{a}_{9} \mathrm{a}_{10}$.

2) Use linear function group to define the area scope, convert the terrain image data to coordinate location data.

Step 3: The position of longitude and latitude data of $\mathrm{a}_{1}$ to $\mathrm{a}_{10}$ can be recorded as $\mathrm{a}_{1}\left(\mathrm{x}_{1}, \mathrm{y}_{1}\right)$ to $\mathrm{a}_{10}\left(\mathrm{x}_{10}, \mathrm{y}_{10}\right)$. Line-segment $\mathrm{a}_{1} \mathrm{a}_{2}$ expressed as $\frac{y_{1}-y_{2}}{x_{1}-x_{2}} X-Y+\frac{y_{2} x_{1}-y_{1} x_{2}}{x_{1}-x_{2}}=0,\left(x_{1} \leq x \leq x_{2}\right)$. All the edges of the triangles of Spot $\mathrm{A}$ and Spot $\mathrm{B}$ can be expressed as the above formula.

Step 4: Get the location of point $M\left(x_{m}, y_{m}\right)$, pick out all line-segments that includes $x_{m}$. In this case, they are $\mathrm{a}_{1} \mathrm{a}_{9}, \mathrm{a}_{1} \mathrm{a}_{7}, \mathrm{a}_{1} \mathrm{a}_{6}, \mathrm{a}_{1} \mathrm{a}_{5}, \mathrm{a}_{1} \mathrm{a}_{4}$ and $\mathrm{a}_{1} \mathrm{a}_{3}$.

Step 5: Pick out all the triangles that are relates to $a_{1} a_{9}, a_{1} a_{7}, a_{1} a_{6}, a_{1} a_{5}, a_{1} a_{4}, a_{1} a_{3}$. They are $\Delta \mathrm{a}_{1} \mathrm{a}_{7} \mathrm{a}_{9}, \quad \Delta \mathrm{a}_{1} \mathrm{a}_{6} \mathrm{a}_{7}, \quad \Delta \mathrm{a}_{1} \mathrm{a}_{5} \mathrm{a}_{6}, \quad \Delta \mathrm{a}_{1} \mathrm{a}_{4} \mathrm{a}_{5}, \quad \Delta \mathrm{a}_{1} \mathrm{a}_{3} \mathrm{a}_{4}$ and $\Delta \mathrm{a}_{1} \mathrm{a}_{2} \mathrm{a}_{3}$.

Step 6: Determine the relationship between Point $M$ and all the triangles which were picked out by step 6. The result is that Point $\mathrm{M}$ is in the range of $\Delta \mathrm{a}_{1} \mathrm{a}_{7} \mathrm{a}_{9}$.

Step 7: As step 2 shows, the $\Delta \mathrm{a}_{1} \mathrm{a}_{7} \mathrm{a}_{9}$ belongs to Spot $\mathrm{A}$ area, so does the Point $\mathrm{M}$.

\section{Solutions of the best tour route generation}

The essence of the touring route planning and design work is selecting appropriate sites based on certain criteria and designing reasonable route planning to generate a complete route design. In the scenic spot tour, visitors must visit in a certain order. When time is not enough, visitors need to choose the appropriate route. Generally speaking, the visitors always hope to visit the most iconic and distinctive scenic areas as many as possible.

An article entitled“ Analysis on Campus Mathematical Model of Optimal Route” [8] introduces the problem processing model analysis, which provides reference of modeling for this paper. To put travel route planning problem into optimal route design problem from graph theory perspective.

Dijkstra algorithm in graph theory is used for classical algorithm of shortest path problem between nodes [9]. Dijkstra algorithm is breadth-first traversal variation to a certain extent. As to research questions in this paper, its advantage is that the results is a node has shortest path to all other nodes in the graph. This feature allows the tour route design strategy to be more reasonable and comprehensive and can improve the efficiency of selecting attractions in the scenic spots.

The basic ideas of best tour route design are as follows: 
(a). To gather relevant geographic information, transform these information into digital model of undirected graph.

(b). To take advantage of the classical Dijkstra shortest path algorithm to get the shortest path in the picture by nodes each representing the gateway or destination node to other nodes.

(c). According to designed standards which measure the value of a particular attraction, to set the relevant data for all attractions in the scenic area.

(d). Based on result in (b) and (c), to find out the the scenic spot set and path set, and design the best order to visit in limited time which meets conform to the requirements.

\section{Summary}

Based on large amount of information contained in the data base of scenic spots, this paper considers the personalized needs of tourists. And regarding it as a starting point and goal, this paper has designed intelligent tourist guide system. The research goal is its final results can meet the practical needs. The author continuously adjusted the design ideas and measures of system development technology, selected to design the generation algorithm of the best tour routes designing, from selection of the measuring real-time positioning technology to intelligent tourist guide system. All these are for the ultimate goal that the system will be more intelligent, comprehensive and practical.The current phase of the system has been basically completed.

\section{References}

[1] Wu Qianjin, Meng Qinglong. Research on the application and development of electronic guide [J]. Software Tribune, 2013: 3(12): 15-16.

[2] Gregory D. Abowd, Christopher G.Atkeson, Jason Hong, et al. Cyberguide: A mobile context-aware tour guide [J]. Wireless Networks, 1997, 3(5): 421-433.

[3] H.H. Owaied, H.A. Farhan, N. Al-Hawamdeh, et al. A Model for Intelligent Tourism Guide System [J]. Journal of Applied Sciences, 2011, 11(2): 342-347.

[4] Guo Junfeng. Research on self-help electronic guide system [D]. Qingdao: Qingdao University, 2007.

[5] Liu Tao, He Ning, Yang Yimin.The application of RFID in portable intelligent navigation system [J]. Engineering and Computer Science, 2011(6): 168-172.

[6] Zhang Li. The design and realization of the positioning system based on the technology of WiFi [D]. BeiJing: Beijing University of Posts and Telecommunications, 2009.

[7] Tian Shijun. High sensitivity GPS positioning and integrated navigation technology research [D]. Cheng Du: University of Electronic Science and Technology, 2009.

[8] Liao Chuanrong. Campus best route problem analysis of the mathematical model [J]. University mathematics, 2012, 28(6): 78-82.

[9] Li Yuanchen. Network shortest path based on Dijkstra algorithm analysis [J]. Micro Computer Application, 2004, 25(3): 295-362. 